\title{
The conductivity and band structure of some synthetic semiconductors based on $\mathrm{M}(\mathrm{dmit})_{2}(\mathrm{M}=\mathrm{Ni}, \mathrm{Pd}, \mathrm{Pt})$
}

\author{
G J Kramer $\dagger$, J C Jol $\dagger$, H B Brom $\dagger$, L R Groeneveld $\ddagger$ and J Reedijk $\ddagger$ \\ $\dagger$ Kamerlingh Onnes Laboratory, Leiden University, PO Box 9506, 2300 RA-Leiden, \\ The Netherlands \\ ¥ Gorlaeus Laboratories, Leiden University, PO Box 9502, 2300 RA-Leiden, The \\ Netherlands
}

Received 23 March 1988

\begin{abstract}
The conductivity of the following six new low-dimensional compounds is reported: $\left(\mathrm{Me}_{4} \mathrm{~N}\right)\left[\mathrm{Ni}(\mathrm{dmit})_{2}\right],\left(\mathrm{Et}_{4} \mathrm{~N}\right)\left[\mathrm{Ni}(\mathrm{dmit})_{2}\right],\left(\mathrm{Pr}_{4} \mathrm{~N}\right)\left[\mathrm{Ni}(\mathrm{dmit})_{2}\right],\left(\mathrm{Bu}_{4} \mathrm{~N}\right)\left[\left(\mathrm{Ni}(\mathrm{dmit})_{2}\right]\right.$, $\left(\mathrm{Bu}_{4} \mathrm{~N}\right)\left[\mathrm{Pt}(\mathrm{dmit})_{2}\right]$ and $\left(\mathrm{Et}_{4} \mathrm{~N}\right)_{0.5}\left[\mathrm{Pd}(\mathrm{dmit})_{2}\right]$. Semiconducting behaviour is found for all the compounds investigated, with activation energies between 0.1 and $0.5 \mathrm{eV}$. The crystal structures have been established by $x$-ray diffraction. Using these, the band structure has been determined. It is shown that the compounds investigated are semiconductors each having a correlation gap resulting from an effective electron-electron repulsion of $1.0 \mathrm{eV}$.
\end{abstract}

\section{Introduction}

Charge-transfer compounds based on bis(1,3-dithiole-2-thione-4,5-dithiolato)niccolate(III) (henceforth $\mathrm{Ni}(\mathrm{dmit})_{2}$ ) have recently attracted much attention. With different donor molecules, various research groups have synthesised compounds that display either superconductivity (TTF $\left[\mathrm{Ni}(\mathrm{dmit})_{2}\right]_{2}$, Brossard et al (1986); $\left(\mathrm{Me}_{4} \mathrm{~N}\right)_{0.5}\left[\mathrm{Ni}(\mathrm{dmit})_{2}\right]$, Kajita et al (1988)), metallic conductivity (e.g. [(n-Bu $\left.)_{4}\right]_{0.29}$ [Ni(dmit) ${ }_{2}$, Valade et al (1983)) or semiconductivity (this paper and, e.g., for $\operatorname{TTF}\left[\operatorname{Pd}(\mathrm{dmit})_{2}\right]_{2}$ and $\operatorname{TTF}\left[\mathrm{Pt}(\mathrm{dmit})_{2}\right]_{3}$, Bousseau et al (1986)). In this paper we study the conductivity of six compounds within the series $\left(\mathrm{R}_{4} \mathrm{~N}\right)_{x}\left[\mathrm{M}(\mathrm{dmit})_{2}\right](\mathrm{M}=\mathrm{Ni}, \mathrm{Pd}, \mathrm{Pt} ; \mathrm{R}=$ methyl (Me), ethyl (Et), propyl (Pr) and butyl (Bu); and $x=0.5,1):\left(\mathrm{Me}_{4} \mathrm{~N}\right)\left[\mathrm{Ni}(\mathrm{dmit})_{2}\right]$, $\left(\mathrm{Et}_{4} \mathrm{~N}\right)\left[\mathrm{Ni}(\mathrm{dmit})_{2}\right], \quad\left(\mathrm{Pr}_{4} \mathrm{~N}\right)\left[\mathrm{Ni}(\mathrm{dmit})_{2}\right], \quad\left(\mathrm{Bu}_{4} \mathrm{~N}\right)\left[\mathrm{Ni}\left(\mathrm{dmit}_{2}\right], \quad\left(\mathrm{Bu}_{4} \mathrm{~N}\right)\left[\mathrm{Pt}\left(\mathrm{dmit}_{2}\right]\right.\right.$ and $\left(\mathrm{Et}_{4} \mathrm{~N}\right)_{0.5}\left[\mathrm{Pd}(\mathrm{dmit})_{2}\right]$, all of which display semiconducting behaviour. For all six compounds the crystal structure has been determined. This allows us to calculate the wavefunction overlap between valence orbitals of adjacent $\mathrm{M}(\mathrm{dmit})_{2}$ ions, which is proportional to the transfer integral. The purpose of this paper is to relate the observed activation energy for the conductivity to the outcome of the tight-binding band-structure calculations. We will show that, under the assumption that the on-site Coulomb repulsion is much larger than the band width, the activation energies can be explained.

The organisation of the paper is as follows. First, the crystal structures will be discussed, with special emphasis on the $\mathrm{M}(\mathrm{dmit})_{2}$ groups $(\S 2)$. In $\S 3$, the experimental results of the conductivity measurements are presented. In $\$ 4$ the band structures are 
calculated. The last two sections are devoted to a comparison of observed and calculated gap values.

\section{The preparation and crystal structure of $\left(R_{4} N\right)_{x}\left[M(d m i t)_{2}\right]$}

The dianionic salts $\left(\mathrm{R}_{4} \mathrm{~N}\right)_{2}\left[\mathrm{M}(\mathrm{dmit})_{2}\right]$ were prepared following a synthesis route described in the literature (Steimecke et al 1979, Kato et al 1984, Valade et al 1985). From this, the $\left(\mathrm{R}_{4} \mathrm{~N}\right)_{x}\left[\mathrm{M}(\mathrm{dmit})_{2}\right](x=1,0.5)$ coordination compounds are synthesised either by oxidation with iodine, or by autoxidation as described by Steimecke et al (1979).

As details regarding the crystal structure have been or will be published elsewhere we restrict ourselves to features relevant to the electronic structure. $\mathrm{M}(\mathrm{dmit})_{2}$ compounds exhibit widely different forms of molecular packing (see, e.g., Kobayashi et al (1987) and references therein). Within the series considered in this paper, we encounter both 3D networks, 2D sheets and linear chains.

$\left(\mathrm{Me}_{4} \mathrm{~N}\right)\left[\mathrm{Ni}(\mathrm{dmit})_{2}\right]$ (Van Diemen et al 1988) features two crystallographically inequivalent $\mathrm{Ni}$ (dmit) ${ }_{2}$ groups, which are intricately stacked to form a structure resembling a winding staircase. There are no important $\mathrm{Ni}-\mathrm{S}$ contacts between the anions: the shortest distance ( $3.98 \AA)$ is significantly larger than the van der Waals radius $(3.48 \AA)$. The anions are stacked, side by side, in pairs with the central $\mathrm{Ni}$ atoms at relatively large distances. Inter-molecular contacts between the $\left[\mathrm{Ni}(\mathrm{dmit})_{2}\right]^{-}$ions are formed by $\mathrm{S}-\mathrm{S}$ contacts varying from 3.231 to $3.697 \AA$ in distance, i.e. shorter than the corresponding van der Waals radius $(3.70 \AA)$.

$\left(\mathrm{Et}_{4} \mathrm{~N}\right)\left[\mathrm{Ni}(\mathrm{dmit})_{2}\right]$ (Groeneveld et al 1986, Kramer et al 1987) is a one-dimensional system with zig-zag chains separated by the donor groups (see figure 1). The structure contains quasi-planar $\left[\mathrm{Ni}(\mathrm{dmit})_{2}\right]^{-}$ions, stacked face to face with alternating $\mathrm{Ni}-\mathrm{Ni}$ distances of 4.163 and $4.243 \AA$. Several short inter-molecular $S-S$ contacts between the $\left[\mathrm{Ni}(\mathrm{dmit})_{2}\right]^{-}$ions within the chain were found from 3.660 to $3.711 \AA$. Also a short Ni-S contact within a 'dimer' exists of $3.506 \AA$.

$\left(\mathrm{Pr}_{4} \mathrm{~N}\right)\left[\mathrm{Ni}\left(\mathrm{dmit}_{2}\right]\right.$ (Van Diemen et al 1988) contains dimers of anions with short S-S contacts $(3.496 \AA)$. The dimers themselves are arranged in layers separated by the $\left(\operatorname{Pr}_{4} N\right)^{+}$ions (see figure 2 ).

The structure of $\left(\mathrm{Bu}_{4} \mathrm{~N}\right)\left[\mathrm{Ni}(\mathrm{dmit})_{2}\right]$ (Lindquist et al 1982) can be described as a 2D network of S-S contacts $(3.514-3.611 \AA)$. There are no short inter-molecular S-S

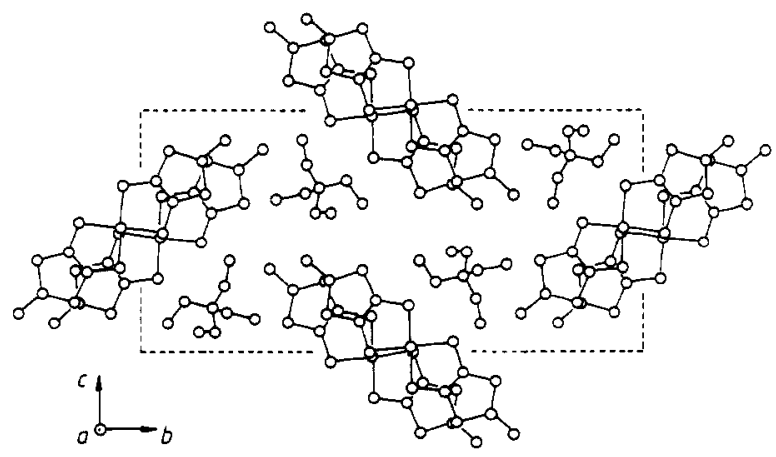

Figure 1. The structure of $\left(\mathrm{Et}_{4} \mathrm{~N}\right)\left[\mathrm{Ni}(\mathrm{dmit})_{2}\right]$. The stacking axis is normal to the $b c$ plane. The broken line is the projection of the unit cell. 


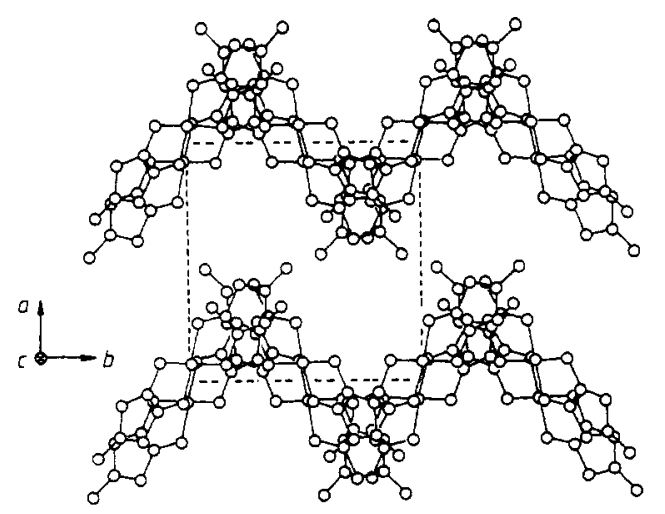

Figure 2. The structure of $\left(\operatorname{Pr}_{4} \mathrm{~N}\right)\left[\mathrm{Ni}(\mathrm{dmit})_{2}\right]$. The projection is along the $c$ axis. The layer of dimers lies in the $b c$ plane. The $\operatorname{Pr}_{4} \mathrm{~N}$ groups have been omitted for clarity.

contacts in the direction perpendicular to this plane. The 'isolated' layers of anionic molecules are separated by the large $\left(\mathrm{Bu}_{4} \mathrm{~N}\right)^{+}$ions.

$\left(\mathrm{Bu}_{4} \mathrm{~N}\right)\left[\mathrm{Pt}(\mathrm{dmit})_{2}\right]$ (Von Marinelli et al 1988) consists of monomeric units, in which the $\mathrm{Pt}$ (III) ions are positioned at centres of symmetry. One important feature of this structure is the exclusive side-by-side intra-chain stacking of the completely planar units along the $z$ axis, in contrast to the face-to-face stacking found in, e.g., $\left(\mathrm{Et}_{4} \mathrm{~N}\right)\left[\mathrm{Ni}\left(\mathrm{dmit}_{2}\right]\right.$, The anionic chains are separated from each other by chains formed by the $\left[\left(\mathrm{C}_{4} \mathrm{H}_{9}\right)_{4} \mathrm{~N}\right]^{+}$ ions. Within the chain, formed by the $\mathrm{Pt}(\mathrm{dmit})_{2}^{-}$ions, the neighbouring anions are rotated by approximately $75^{\circ}$ with respect to each other. The shortest inter-stack S-S distance is $3.557 \AA$.

$\left(\mathrm{Et}_{4} \mathrm{~N}\right)_{0.5}\left[\mathrm{Pd}(\mathrm{dmit})_{2}\right]$ (Groeneveld et al 1988) has a stoichiometry differing from that of the above compounds. The unit cell comprises two Pd(dmit $)_{2}$ ions, with a total charge of minus one, which are arranged in sheets separated by a layer of tetra-ethylammonium cations. Within these sheets a chain can be identified with Pd-Pd distances of 3.231 and $5.284 \AA$ while S-S distances range from 3.26 to $3.72 \AA$. This difference arises because in this compound, in contrast to the ones mentioned above, the anion is not flat. The two dmit ligands have an inclination of about $7^{\circ}$ with one another, making the molecular unit V-shaped.

\section{Conductivity experiments}

Conductivity experiments were performed on single crystals with typical dimensions of $1 \times 0.1 \times 0.1 \mathrm{~mm}^{3}$. Thin gold wires, $30 \mu \mathrm{m}$ in diameter, were glued to the crystals with silver paint (Electrodag 1415). All measurements were made in a two-probe configuration since the impedances are so high that it is not necessary to perform four-probe measurements. Temperatures between 50 and $400 \mathrm{~K}$ were obtained in a continuous-flow cryostat (Oxford Instruments), or in a conventional He bath cryostat. The temperature stability was better than $1 \mathrm{~K}$. The data were taken at a cooling (warm-up) rate of approximately $1 \mathrm{~K} \mathrm{~min}^{-1}$. The conductivity was measured with a Keithley model 617 electrometer using a constant voltage of $1 \mathrm{~V}$. This enabled us to measure impedances up to $10^{13} \Omega$. 


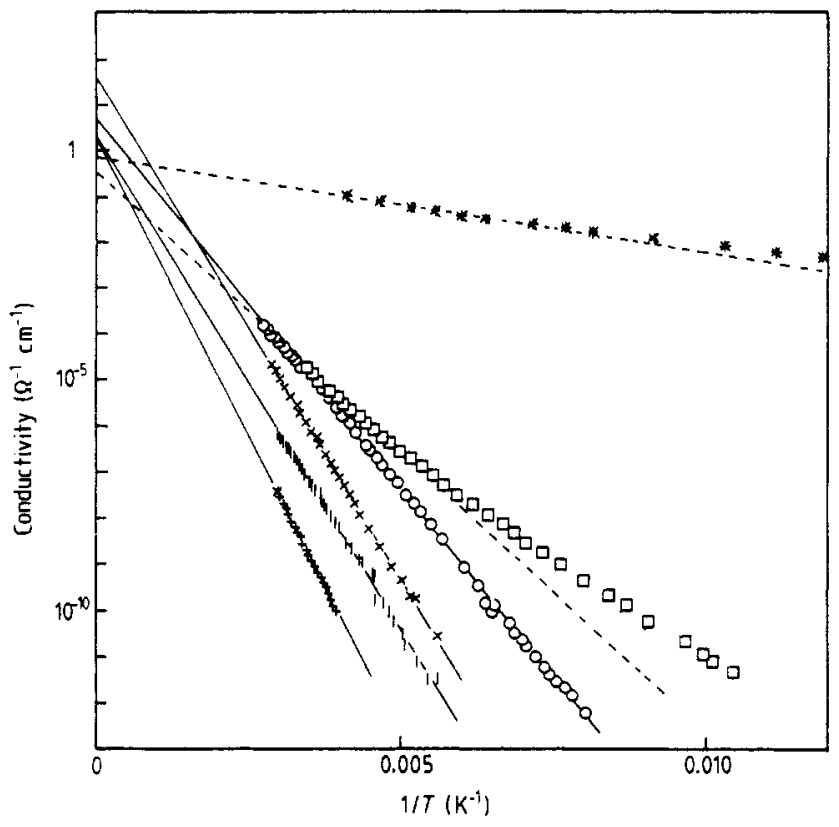

Figure 3. The temperature dependence of the conductivity for $\left(\mathrm{Me}_{4} \mathrm{~N}\right)\left[\mathrm{Ni}(\mathrm{dmit})_{2}\right]$ (circles), $\left(\mathrm{Et}_{4} \mathrm{~N}\right)\left[\mathrm{Ni}(\mathrm{dmit})_{2}\right]$ (squares), $\left(\mathrm{Pr}_{4} \mathrm{~N}\right)\left[\mathrm{Ni}(\mathrm{dmit})_{2}\right]$ (bars), $\left(\mathrm{Bu}_{4} \mathrm{~N}\right)\left[\mathrm{Ni}(\mathrm{dmit})_{2}\right]$ (plus signs), $\left(\mathrm{Bu}_{4} \mathrm{~N}\right)\left[\operatorname{Pr}(\mathrm{dmit})_{2}\right]$ (crosses) and $\left(\mathrm{Et}_{4} \mathrm{~N}\right)_{0.5}\left[\mathrm{Pd}(\mathrm{dmit})_{2}\right]$ (asterisks).

Figure 3 shows the conductivity of the six compounds under consideration. The temperature dependence of the conductivity may be expressed as

$$
\sigma(T)=\sigma_{0} \exp \left(-E_{\mathrm{a}} / k_{\mathrm{B}} T\right) \text {. }
$$

The values of the activation energy $E_{\mathrm{a}}$ and the conductivity prefactor $\sigma_{0}$ are listed in table 1. As seen from figure 3, for $\left(\mathrm{Et}_{4} \mathrm{~N}\right)\left[\mathrm{Ni}(\mathrm{dmit})_{2}\right]$ and $\left(\mathrm{Et}_{4} \mathrm{~N}\right)_{0.5}\left[\mathrm{Pd}(\mathrm{dmit})_{2}\right]$ there are deviations from the simple semiconductor expression (3.1). In the latter case the behaviour is described by

$$
\sigma(T)=\sigma_{0} \exp \left[-\left(E_{\mathrm{a}}^{\prime} / k_{\mathrm{B}} T\right)^{1 / 2}\right]
$$

Such a temperature dependence can be interpreted as regular semiconducting behaviour with a temperature-dependent gap $E_{\mathrm{a}}=\left(E_{\mathrm{a}}^{\prime} / T\right)^{1 / 2}$, but often it is associated with dis-

Table 1. Conductivity parameters of $\left(\mathrm{R}_{4} \mathrm{~N}\right)_{x}\left[\mathrm{M}(\mathrm{dmit})_{2}\right]$.

\begin{tabular}{lll}
\hline Compound & $E_{\mathrm{a}}(\mathrm{eV})$ & $\sigma_{0}\left(\Omega^{-1} \mathrm{~cm}^{-1}\right)$ \\
\hline$\left(\mathrm{Me}_{4} \mathrm{~N}\right)\left[\mathrm{Ni}(\mathrm{dmit})_{2}\right]$ & 0.32 & 4.8 \\
$\left(\mathrm{Et}_{4} \mathrm{~N}\right)\left[\mathrm{Ni}(\mathrm{dmit})_{2}\right]$ & $0.25 \dagger$ & 0.4 \\
$\left(\mathrm{Pr}_{4} \mathrm{~N}\right)\left[\mathrm{Ni}(\mathrm{dmit})_{2}\right]$ & 0.43 & 2.1 \\
$\left(\mathrm{Bu}_{4} \mathrm{~N}\right)\left[\mathrm{Ni}(\mathrm{dmit})_{2}\right]$ & 0.51 & 1.8 \\
$\left(\mathrm{Bu}_{4} \mathrm{~N}\right)\left[\mathrm{Pt}(\mathrm{dmit})_{2}\right]$ & 0.43 & 38 \\
$\left(\mathrm{Et}_{4} \mathrm{~N}\right)_{0.5}\left[\mathrm{Pd}(\mathrm{dmit})_{2}\right]$ & $0.10^{\dagger}$ & 0.7 \\
\hline
\end{tabular}

† Since the gap is temperature dependent, the room-temperature value is given. 
order (Bloch et al 1972). We will use the room-temperature activation energy for comparison with the calculations of the electronic structure.

With regard to the values of $\sigma_{0}$, one observes that they vary relatively modestly, i.e. within two orders of magnitude. This value (roughly $5 \Omega^{-1} \mathrm{~cm}^{-1}$ ) can be associated with the carrier mobility, using

$$
\sigma_{0}=n_{0} q \mu
$$

where $n_{0}$ is the total electron density, $q$ the electron charge and $\mu$ the mobility; $n_{0} \simeq$ $8 \times 10^{20}$ electrons $\mathrm{cm}^{-3}$, resulting in a mobility of $0.01-0.1 \mathrm{~cm}^{2} \mathrm{~V}^{-1} \mathrm{~s}^{-1}$. Similar values are found for semiconductors within the series of substituted morpholinium $\mathrm{TCNQ}_{2}$ (Visser et al 1982). For typical $1 \mathrm{D}$ metals like TTF-TCNQ 2 the mobility is two orders of magnitude higher (Cohen et al 1974).

\section{Band-structure calculations}

In this section the results of a band-structure calculation for the above-mentioned compounds are presented. The calculation of the band structure of an organic (semi)conductor is always a two-stage process: firstly the valence molecular orbitals of the molecules have to be calculated and only thereafter can one calculate the overlap between neighbouring molecules, which in turn enables one to calculate the band structure. This division is necessary since the energy scale of chemical bonding within the molecule is a few orders of magnitude higher than the transfer integrals linking them together.

We will assume that the electron Hamiltonian for the system is of the form

$$
\mathscr{H}=\sum_{i \neq j, \sigma} t_{i j}\left(c_{i \sigma}^{\dagger} c_{j \sigma}+c_{j \sigma}^{\dagger} c_{i \sigma}\right)+\sum_{i, \sigma} \varepsilon_{\alpha} c_{i \sigma}^{\dagger} c_{i \sigma}+\sum_{i} U c_{i \downarrow}^{\dagger} c_{i \downarrow} c_{i \uparrow}^{\dagger} c_{i \uparrow}
$$

where $t_{i j}$ is the transfer integral, $\varepsilon_{\alpha}$ is a site-dependent Madelung energy ( $\alpha$ denotes crystallographically different sites) and $U$ is the on-site (Hubbard) electron-electron repulsion. We note that the transfer integrals and local potentials are different for all systems, whereas the value of the Hubbard parameter $U$ is approximately constant for a given acceptor molecule and a fixed band filling. The Hubbard Hamiltonian is in general insoluble, but its limits are well known: if $U \ll W$ where $W$ is the band width, a half-filled system is metallic with Pauli-like susceptibility. If, on the other hand, $U$ exceeds the band width, the system is an insulator with weak antiferromagnetic exchange $J=4 t^{2} / U$; the band is split in two identical parts with an energy separation $U$. The task we set ourselves in this section is to calculate the transfer integrals.

Molecular orbitals of neutral $\mathrm{Ni}(\mathrm{dmit})_{2}$ and $\mathrm{Pt}(\mathrm{dmit})_{2}$ units were obtained from an extended Hückel calculation (Howell et al 1980). The atomic orbitals are of Slater type:

$$
\left|\varphi^{\mathrm{AO}}\right\rangle=(2 \xi)^{n+1 / 2}[(2 n) !]^{-1 / 2} r^{n-1} \mathrm{e}^{-\xi r} Y_{l m}(\theta, \varphi) .
$$

For the different atoms, the radii and principal quantum numbers are listed in table 2 . The resulting molecular orbitals, linear combinations of (4.2), are shown in figure 4 . The differences between $\mathrm{Ni}$ and $\mathrm{Pt}$ molecules are minor and mainly affect the metal atom; the ligand orbitals hardly change at all. Since no parameters were known for $\mathrm{Pd}$, we have used for the latter the average of $\mathrm{Ni}$ and $\mathrm{Pt}$. The $\mathrm{Ni}(\mathrm{dmit})_{2}$ orbital is quite similar to the ones obtained by Kobayashi et al (1987).

The overlap between molecular orbitals on adjacent $\mathrm{M}(\mathrm{dmit})_{2}$ units can be calculated 
Table 2. Slater orbital data.

\begin{tabular}{lllc}
\hline Atom & Orbital & Coefficient & $\zeta\left(\AA^{-1}\right)$ \\
\hline $\mathrm{C}$ & $2 \mathrm{p}_{z}$ & & 3.072 \\
$\mathrm{~S}$ & $3 \mathrm{p}_{z}$ & & 3.445 \\
$\mathrm{Ni}{ }^{\dagger}$ & $3 \mathrm{~d}_{x z}$ & 0.610 & 10.87 \\
& & 0.512 & 4.91 \\
$\mathrm{Pd}{ }^{\dagger}$ & $4 \mathrm{~d}_{x z}$ & 0.619 & 11.31 \\
& & 0.529 & 4.94 \\
$\mathrm{Pt} \dagger$ & $5 \mathrm{~d}_{x z}$ & 0.633 & 11.37 \\
& & 0.551 & 5.10 \\
\hline
\end{tabular}

† The $d_{x z}$ orbitals are contracted (Basch and Gray 1966).

numerically, using a scheme developed by Roothaan (1951). The overlap, $S$, is proportional to the transfer integrals (Berlinsky et al 1974, Grant 1983):

$$
t_{i j}=K S_{i j}\left(E_{i}+E_{j}\right) / 2
$$

where $E_{i}$ and $E_{j}$ are the ionisation energies of the relevant orbital, i.e. the LUMO of the neutral molecule, and $K$ is a constant between 1 and 2 (usually taken as 1.75). The calculated ionisation energy is $9.5 \mathrm{eV}$, both for $\mathrm{Ni}(\mathrm{dmit})_{2}$ and $\mathrm{Pt}(\mathrm{dmit})_{2}$. Therefore, we also use

$$
t_{i j}=17 S_{i j}(\mathrm{eV}) .
$$

Our values for $S_{i j}$ are systematically larger by a factor of 1.7 than those obtained by Kobayashi et al (1987). The origin of this discrepancy is not known; we can merely state that our wavefunctions are properly normalised and that the configurational dependence of the overlap is the same as obtained by Kobayashi and co-workers.
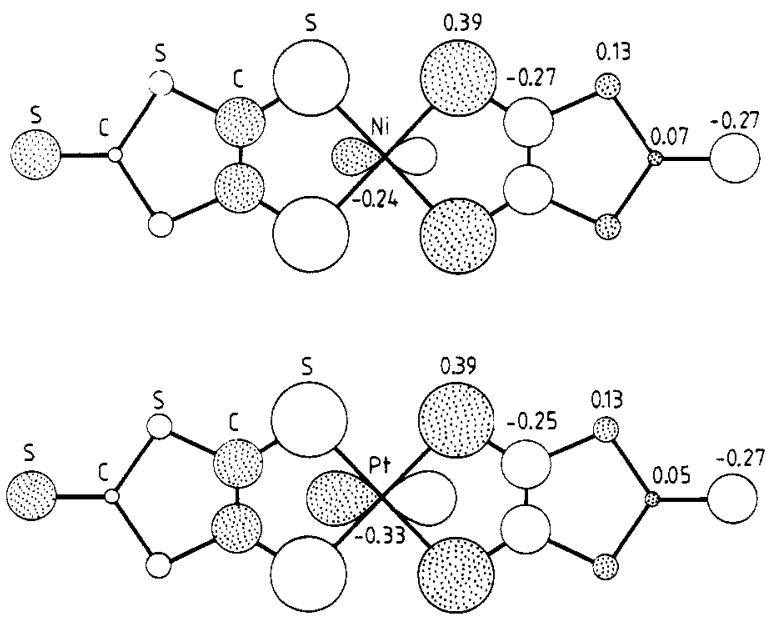

Figure 4. Molecular orbitals of $\mathrm{Ni}(\mathrm{dmit})_{2}$ and $\mathrm{Pt}(\mathrm{dmit})_{2}$. Carbon and sulphur orbitals are of the $\mathrm{p}_{z}$ type, while those of nickel and platinum are of the $\mathrm{d}_{x z}$ type. Radii and quantum numbers are listed in table 2. 


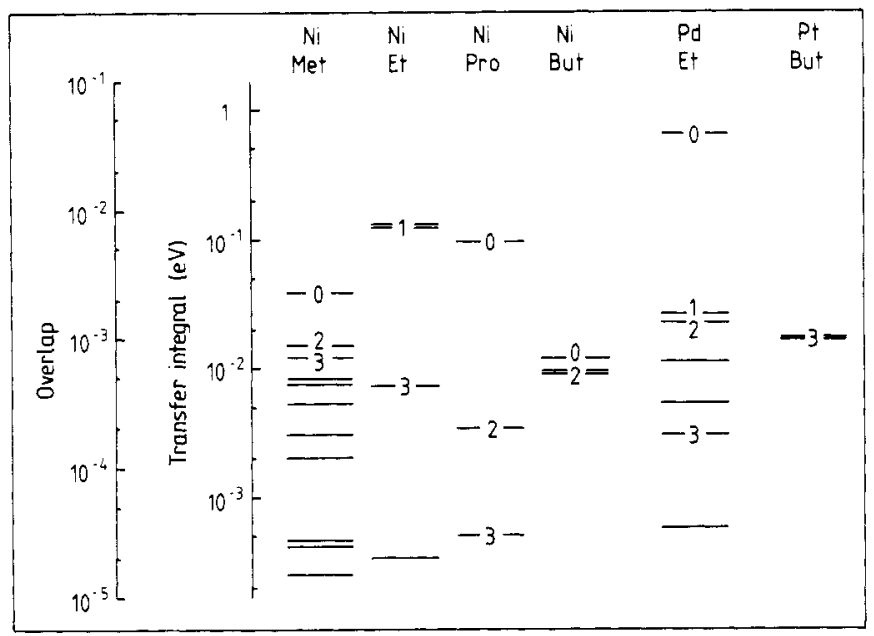

Figure 5. Inter-molecular overlaps for six $\left(\mathrm{R}_{4} \mathrm{~N}\right)_{x}\left[\mathrm{M}(\mathrm{dmit})_{2}\right]$ compounds. The heading gives the metal atom and the alkyl group; $x=1$ for all except $\left(\mathrm{Et}_{4} \mathrm{~N}\right)_{0.5}\left[\mathrm{Pd}(\mathrm{dmit})_{2}\right]$. The numbers associated with the overlaps denote the dimensionality of the system if smaller transfer integrals are neglected: 0 implies a dimer, 1 a chain etc (see the text).

All overlaps have been calculated for the six compounds. Overlaps exceeding $10^{-5}$ are shown graphically in figure 5 . The numbers assigned to the overlaps denote the dimensionality of the system if the smaller overlaps are neglected. $\left(\mathrm{Et}_{4} \mathrm{~N}_{0.5}\right)\left[\mathrm{Pd}(\mathrm{dmit})_{2}\right]$ is taken as an example: a large transfer integral $(0.63 \mathrm{eV})$ couples two $\mathrm{Pd}(\mathrm{dmit})_{2}$ groups to dimers, denoted by 0 . Two subsequent transfer integrals $(0.026$ and $0.022 \mathrm{eV})$ interconnect these dimers. The first one occurs twice as often as the second and forms chains (1); with the second a $2 \mathrm{D}$ network is constructed (2). Two extra transfer integrals strengthen this layer. The first transfer integral that couples neighbouring layers (3) has a value of $2.9 \times 10^{-3} \mathrm{eV}$. The transfer integrals were used to determine the electronic density of states (DOS) in the interactionless limits $U=0$ and $U \gg W$ ( $W$ denotes the band width). In the first case, the band is half-filled (quarter-filled for the Pd compound). In the limit where $U$ exceeds $W$, one has two identical bands, separated by an energy $U$ (Hubbard 1965). The lower one is then completely filled (half-filled for Pd). The results are shown in figure 6 . For $\left(\mathrm{Me}_{4} \mathrm{~N}\right)\left[\mathrm{Ni}(\mathrm{dmit})_{2}\right]$ the result lacks the unambiguity of the other DOS pictures, since in this case two crystallographically independent sites are present. This gives rise to the possibility of different site energies (see equation (1)), which broaden and split the band. The effect is shown in figure $6(a)$. Table 3 lists the band widths and the dimensionality of the electronic system. The calculated anisotropies are in agreement with what might have been anticipated on the basis of the structural descriptions given in $\$ 2$. From examination of the values of atom-to-atom overlaps it was found that the $\mathrm{S}-\mathrm{S}$ contacts determine the total molecule-to-molecule overlap.

All M(dmit $)_{2}$ species, with the exception of $\mathrm{Pd}(\mathrm{dmit})_{2}$, are flat. In the latter case we have performed two different calculations to study the effect of the molecular bending. First the $z$ axis of the reference frame for the atomic $\mathrm{p}_{z}$ and $\mathrm{d}_{x z}$ orbitals was taken to be the mean of the two normal vectors of the dmit planes. In a second calculation, the two dmit groups were handled separately, each with their own reference frame. The difference amounted to only a few per cent. In the above, the (probably more important) changes in the MO of $\mathrm{Pd}(\mathrm{dmit})_{2}$ upon bending have been neglected. 

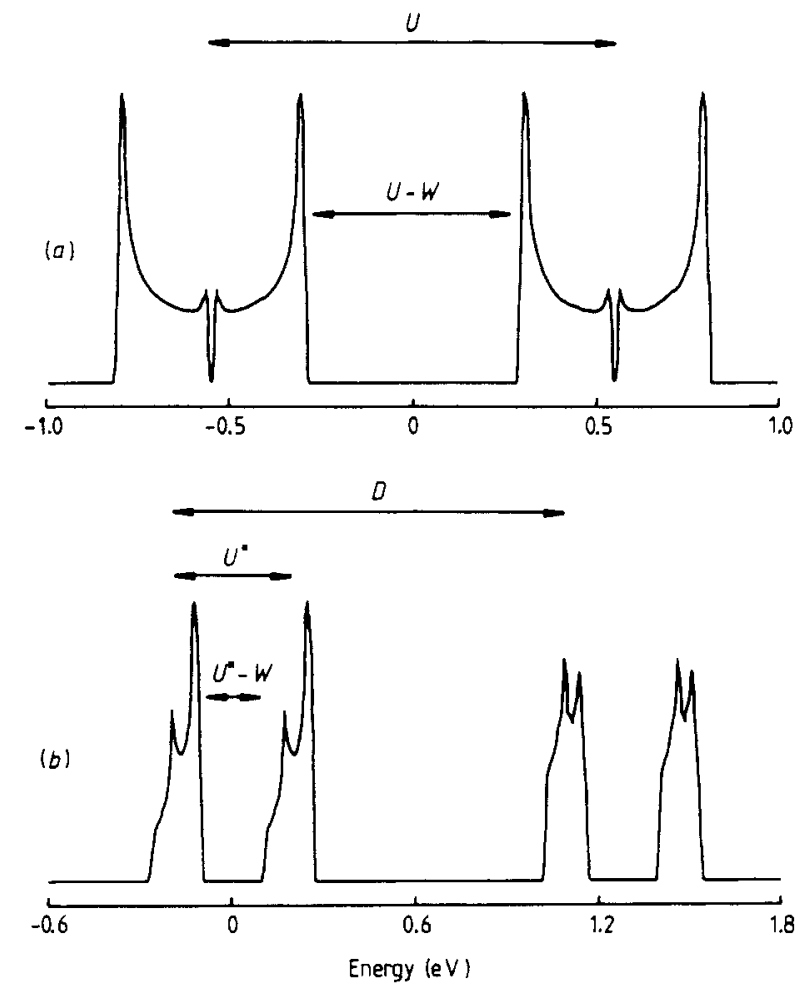

Figure 6. The density of states in arbitrary units: the full trace is the DOS assuming equal onsite energies for the different $\mathrm{Ni}$ (dmit) ${ }_{2}$ molecules; the broken trace is the Dos if $E_{1}=0.1 \mathrm{eV}$ and $E_{2}=-0.1 \mathrm{eV}$, for $\left(\mathrm{Me}_{4} \mathrm{~N}\right)\left[\mathrm{Ni}(\mathrm{dmit})_{2}\right](a),\left(\mathrm{Et}_{4} \mathrm{~N}\right)\left[\mathrm{Ni}(\mathrm{dmit})_{2}\right](b),\left(\mathrm{Pr}_{4} \mathrm{~N}\right)\left[\mathrm{Ni}(\mathrm{dmit})_{2}\right]$ $(c),\left(\mathrm{Bu}_{4} \mathrm{~N}\right)\left[\mathrm{Ni}(\mathrm{dmit})_{2}\right](d),\left(\mathrm{Bu}_{4} \mathrm{~N}\right)\left[\mathrm{Pt}(\mathrm{dmit})_{2}\right](e)$ and $\left(\mathrm{Et}_{4} \mathrm{~N}\right)_{0.5}\left[\mathrm{Pd}(\mathrm{dmit})_{2}\right](f)$. The energies are relative to the centre of the band.

\section{Discussion}

In this section the link will be established between the activation energies obtained from the conductivity experiments and the band-structure data. As noted previously, one assumes the Hubbard $U$-term to be determined primarily by the type of acceptor molecule and band filling.

As can be seen from table 1 and figure 6, the proper limit is $U \gg W$, since otherwise one would expect metallic or semimetallic behaviour. If $U \gg W$, the gap $\Delta\left(=2 E_{\mathrm{a}}\right)$ is $U-W$ (see figure 7). We have used the same $U$-value for all compounds with a $1: 1$ donor to acceptor ratio. In table 4 experimental and calculated gaps are compared with each other, assuming $U$ equal to $1.05 \pm 0.1 \mathrm{eV}$. Note that this value can also be used for the Pt compound, reflecting the minor importance of the metal atom in the determination of electronic properties. Comparison between theory and experiment is most difficult for $\left(\mathrm{Me}_{4} \mathrm{~N}\right)\left[\mathrm{Ni}(\mathrm{dmit})_{2}\right]$ as a consequence of the already mentioned possibility of different site energies. Therefore, only a lower bound for the band width can be given. It would seem that the difference is quite appreciable with respect to the transfer integrals. The value of $E_{1}-E_{2}$ can be estimated to be $\simeq 0.2 \mathrm{eV}$. The agreement thus obtained between theory and experiment is satisfactory. 
Table 3. Calculated band-structure parameters of $\left(\mathrm{R}_{4} \mathrm{~N}\right)_{x}\left[\mathrm{M}(\mathrm{dmit})_{2}\right]$.

\begin{tabular}{lllc}
\hline Compound & Electronic structure & $W_{1 \mathrm{D}}: W_{2 \mathrm{D}}: W_{3 \mathrm{D}}^{\dagger}$ & Bandwidth $\left(10^{3} \mathrm{~S}\right)$ \\
\hline$\left(\mathrm{Me}_{4} \mathrm{~N}\right)\left[\mathrm{Ni}(\mathrm{dmit})_{2}\right]$ & 3D & $1: 1: 0.5$ & $>8.6 \ddagger$ \\
$\left(\mathrm{Et}_{4} \mathrm{~N}\right)\left[\mathrm{Ni}(\mathrm{dmit})_{2}\right]$ & 1D & $1: 0.05: 0.05$ & 31.5 \\
$\left(\mathrm{Pr}_{4} \mathrm{~N}\right)\left[\mathrm{Ni}(\mathrm{dmit})_{2}\right]$ & Sheet of dimers & $1: 1: 0.2$ & 12.3 \\
$\left(\mathrm{Bu}_{4} \mathrm{~N}\right)\left[\mathrm{Ni}(\mathrm{dmit})_{2}\right]$ & 2D & $1: 1: 0.01(?)$ & 5.8 \\
$\left(\mathrm{Bu}_{4} \mathrm{~N}\right)\left[\mathrm{Pt}(\mathrm{dmit})_{2}\right]$ & 3D & $1: 1: 1$ & 8.0 \\
$\left(\mathrm{Et}_{4} \mathrm{~N}\right)_{0.5}\left[\mathrm{Pd}(\mathrm{dmit})_{2}\right]$ & Anisotropic dimer system & $1: 0.4: 0.05$ & $10.4 \S$ \\
\hline
\end{tabular}

† Relative band widths in three crystallographic directions.

\# The quoted value neglects the difference in site energy (see text).

$\S$ The band width of the bonding dimer band.
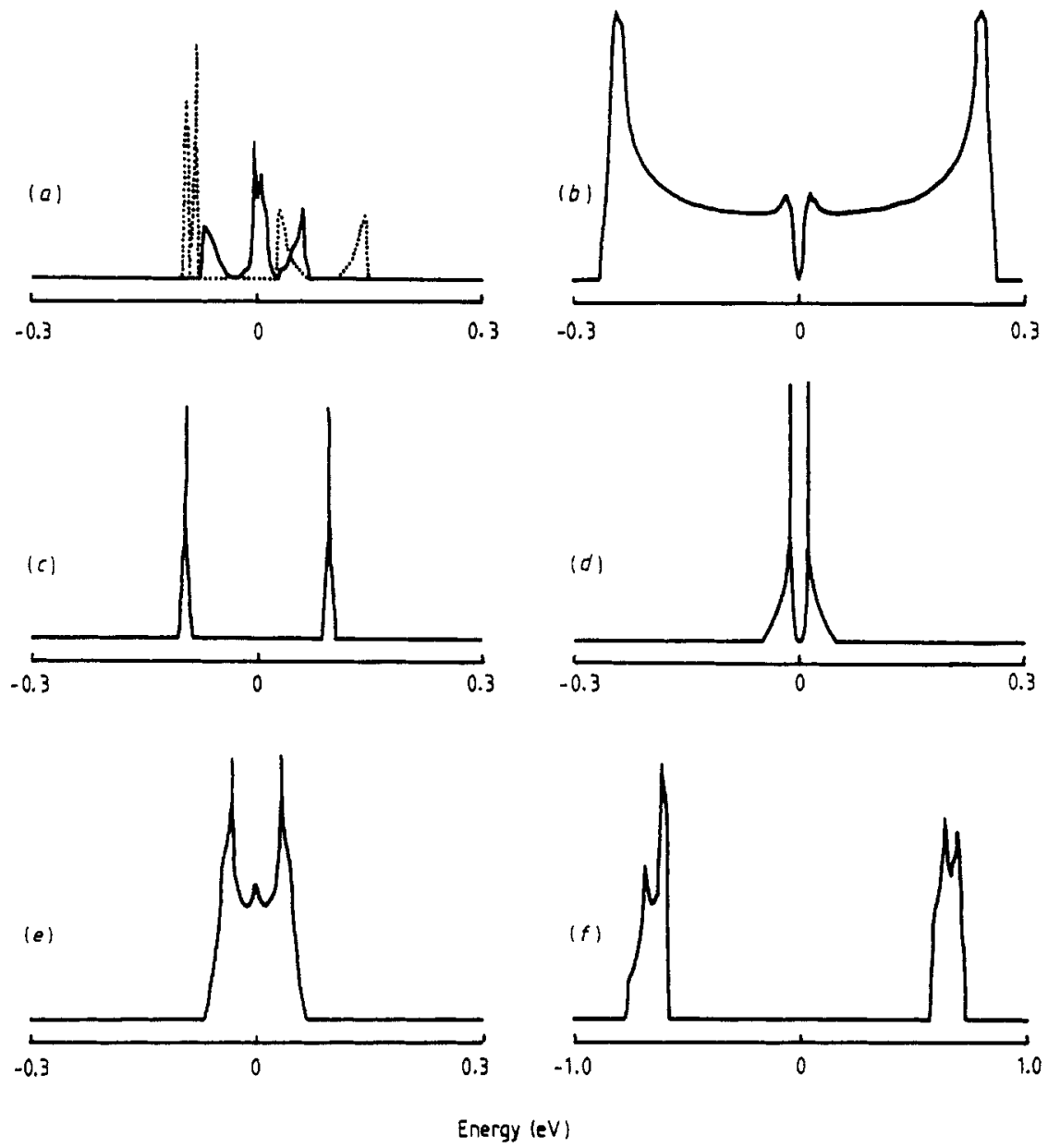

Figure 7. The density of states in the $U \gg W$ limit for $\left(\mathrm{Et}_{4} \mathrm{~N}\right)\left[\mathrm{Ni}(\mathrm{dmit})_{2}\right](a)$ and for $\left(\mathrm{Et}_{4} \mathrm{~N}\right)_{0.5}\left[\mathrm{Pd}(\mathrm{dmit})_{2}\right](b) . D$ is the dimer splitting. 
Table 4. Experimental and theoretical gap values.

\begin{tabular}{llcl}
\hline Compound & $\Delta_{\exp }=2 E_{\mathrm{a}}(\mathrm{eV})$ & $\Delta_{\text {calc }}(\mathrm{eV})$ & $U(\mathrm{eV})$ \\
\hline$\left(\mathrm{Me}_{4} \mathrm{~N}\right)\left[\mathrm{Ni}(\mathrm{dmit})_{2}\right]$ & 0.64 & $<0.90$ & 1.05 \\
$\left(\mathrm{Et}_{4} \mathrm{~N}\right)\left[\mathrm{Ni}(\mathrm{dmit})_{2}\right]$ & 0.50 & 0.51 & 1.05 \\
$\left(\mathrm{Pr}_{4} \mathrm{~N}\right)\left[\mathrm{Ni}(\mathrm{dmit})_{2}\right]$ & 0.86 & 0.84 & 1.05 \\
$\left(\mathrm{Bu}_{4} \mathrm{~N}\right)\left[\mathrm{Ni}(\mathrm{dmit})_{2}\right]$ & 1.02 & 0.95 & 1.05 \\
$\left(\mathrm{Bu}_{4} \mathrm{~N}\right)\left[\mathrm{Pt}(\mathrm{dmit})_{2}\right]$ & 0.86 & 0.91 & 1.05 \\
$\left(\mathrm{Et}_{4} \mathrm{~N}\right)\left[\mathrm{Pd}(\text { dmit })_{2}\right]$ & 0.20 & 0.20 & 0.37 \\
\hline
\end{tabular}

A special place is taken by $\left(\mathrm{Et}_{4} \mathrm{~N}\right)_{0.5}\left[\mathrm{Pd}(\mathrm{dmit})_{2}\right]$. As seen above, this compound consists of dimers. The dimer splitting $D$ (figure 7) is $1.3 \mathrm{eV}$, making it the largest band-structure parameter. This means that all electrons occupy the bonding dimer wavefunction, which has a band width of $0.17 \mathrm{eV}$. This turns the system into an effectively half-filled band system, like the compounds considered previously. The effective Coulomb repulsion is now that for a dimer: $U^{*}=0.35 \pm 0.05 \mathrm{eV}$-substantially less than the value for a single $\mathrm{M}(\mathrm{dmit})_{2}$ ion.

We now return to the temperature dependence of the semiconductor gap in $\left(\mathrm{Et}_{4} \mathrm{~N}\right)\left[\mathrm{Ni}(\mathrm{dmit})_{2}\right]$ and $\left(\mathrm{Et}_{4} \mathrm{~N}\right)_{0.5}\left[\mathrm{Pd}\left(\mathrm{dmit}_{2}\right]\right.$. It was seen that the gap has a value $U-W$. If the temperature is lowered, the transfer integrals increases as a consequence of the decrease in length of the crystal axes. This increases the band width and hence reduces the correlation gap $U-W$. We have estimated the magnitude of this effect, using an estimated thermal expansion parameter $\alpha \simeq 10^{-4} \mathrm{~K}^{-1}$, suitable for organic materials. The increase in band width is of the order of 10 to $20 \%$ going from 300 to $100 \mathrm{~K}$. The smaller the values of $U-W$, the larger the temperature dependence of the gap-this explains why the gap variation is only seen in the compounds with the smallest gaps. This effect, however, is much smaller than that found experimentally $(70 \%)$. In a later paper we will show that the $T^{-1 / 2}$ behaviour of the conductivity can be explained if one takes into account the large thermal motion of the anions.

\section{Conclusion}

We have analysed the semiconductor gap in a series of $\mathrm{M}(\mathrm{dmit})_{2}$ compounds with large cationic 'donor' molecules (tetra-alkylammonium). The gap is determined by the difference between the correlation $U$ and the band width. These systems have band widths of 0.1 to $0.5 \mathrm{eV}$, which is small compared with the on-site Coulomb repulsion $(U)$, for which we found $1.0 \mathrm{eV}$. This value was found to be independent of what the compound was for all 1:1 complexes. Additionally, we have examined one $1: 2$ compound, which consists of dimeric units. In this case, the electron-electron interaction could be described by a dimer $U$ for which a value of $0.35 \mathrm{eV}$ was found.

\section{Acknowledgments}

The authors wish to thank $\mathrm{Dr} J \mathrm{~L}$ Joppe for assistance with early measurements, $\mathrm{Mr}$ Thomas von Marinelli for assistance with the synthesis of some of the compounds, and 
Dr J G Haasnoot for critical reading of the manuscript. This work is part of the research programme of the Leiden Materials Science Centre (Werkgroep Fundamenteel Materialen Onderzoek) and is supported by the 'Stichting FOM' (Foundation for Fundamental Research on Matter) which is sponsored by ZWO (the Netherlands Organisation for the advancement of Pure Research).

\section{References}

Basch H and Gray H B 1966 Theor. Chim. Acta 4367

Berlinsky A J, Carolan J F and Weiler L 1974 Solid State Commun. 15795

Bloch A N, Weisman R B and Varma C M 1972 Phys. Rev. Lett. 28753

Bousseau M, Valada L, Lagros J-P, Cassoux P, Garbauskas M and Interrante L V $1986 \mathrm{~J}$. Am. Chem. Soc. 1081908

Brossard L, Ribault M, Valade L and Cassoux P 1986 Physica B 143378

Cohen M L, Coleman L B, Garito L F and Heeger A J 1974 Phys. Rev. B 101298

Grant P M 1983 J. Physique Coll. 44 C3 847

Groeneveld L R et al 1988 Inorg. Chem. at press

Groeneveld L R, Schuller B, Kramer G J, Haasnoot J G and Reedijk J 1986 Recl. Trav. Chim. Pays-Bas 105507

Howell J, Rossi A, Wallace D, Haraki K and Hoffman R 1980 ICON 8 (FORTRAN program for extended Hückel calculations) unpublished

Hubbard J 1965 Proc. R. Soc. A 281401

Kajita K, Nishio Y, Moriyama S, Kato R, Kobayashi H, Sasaki W, Kobayashi A, Kim H and Sasaki Y 1988 Solid State Commun. 65361

Kato R, Mori T, Kobayashi A, Sasaki Y and Kobayashi H 1984 Chem. Lett. 1

Kobayashi A, Kim H, Sasaki Y, Kato R and Kobayashi H 1987 Solid State Commun. 6257

Kramer G J, Groeneveld L R, Joppe J L, Brom H B, De Jongh L J and Reedijk J 1987 Synth. Met. 19745

Lindquist O, Sjölin L, Sieler J, Steimecke G and Hoyer E 1982 Acta Chem. Scand. A 36853

Roothaan C C J 1951 J. Chem. Phys. 191445

Steimecke G, Sieler H J, Kirmse R and Hoyer E 1979 Phosphorus and Sulfur 749

Valade L, Bousseau M, Gleizes A and Cassoux P 1983 J. Chem. Soc., Chem. Commun. 110

Valade L, Legros J P, Bousseau M, Cassoux P, Garbauskas M and Interrante L V 1985 J. Chem. Soc. Dalton Trans. 783

Van Diemen J H, Groeneveld L R, Lind A, De Graaff R A G, Haasnoot J G and Reedijk J 1988 Acta Crystallogr. C submitted

Visser R J J, Heemstra T W L and de Boer J L 1982 Mol. Cryst. Liq. Cryst. 851425

Von Marinelli T B L W, Groeneveld L R, Haasnoot J G and Reedijk J 1988 unpublished 